Article

\title{
Characterization of Inter-System Biases in GPS + BDS Precise Point Positioning
}

\author{
Cheng Ke ${ }^{1}$, Yanning Zheng ${ }^{1}$ and Shengli Wang ${ }^{2, *}$ \\ 1 College of Geomatics, Shandong University of Science and Technology, Qingdao 266590, China; \\ kcgnss@163.com (C.K.); zhengyn95@gmail.com (Y.Z.) \\ 2 College of Ocean Science and Engineering, Shandong University of Science and Technology, \\ Qingdao 266590, China \\ * Correspondence: shlwang@sdust.edu.cn; Tel.: +86-135-8929-5632
}

Received: 12 June 2020; Accepted: 17 July 2020; Published: 19 July 2020

check for updates

\begin{abstract}
With the combination of multi-GNSS data, the precise-point positioning (PPP) technique can improve its accuracy, availability and reliability: Inter-system bias (ISB) is the non-negligible parameter in multi-GNSS PPP. To further enhance the performance of multi-GNSS PPP, it is crucial to analyze the characterization of inter system biases (ISBs) and model them properly. In this contribution, we comprehensively investigate the characterization of ISBs between global positioning system (GPS) and BeiDou navigation satellite system (BDS) in different situations. (1) We estimate ISB by using different precise products from the Center for Orbit Determination (CODE), Deutsches GeoForschungsZentrum (GFZ) and Wuhan University (WHU). The results indicate that the one-day estimates of ISB are stable when using CODE and WHU products, whereas the estimates based on GFZ products vary remarkably. As for the three-day time series of ISB, a sudden jump exists between two adjacent days, which is due to the change of satellite clock datum; (2) We investigate the ISB characterization affected by the ambient environments of the receivers. The result shows that the ISBs estimated from receivers (and antennas) with same type are still inconsistent, which indicates that the ambient environment, probably the temperature, influences the ISB characterization as well, since the receivers are in different areas; (3) We analyze the ISB characterization affected by receiver and antenna type with the same ambient environment. To ensure the same ambient environment, the ultra-short baselines were applied to investigate the ISB characterization affected by the receiver and antenna type. With the insights into ISB characterizations, we carry out combined GPS and BDS PPP with modeling the ISB as time constant, random walk process and white noise. The results suggest that the random walk process outperforms in most cases, since it strengthens the model to some extend and, at the same time, considers the variation of ISBs.
\end{abstract}

Keywords: inter system biases; global positioning system (GPS); BeiDou navigation satellite system (BDS); multi-GNSS; precise-point positioning (PPP)

\section{Introduction}

With the rapid developments and modernizations of the global navigation satellite systems (GNSSs) including the American GPS, Chinese BDS, European Galileo and Russian GLONASS, the integration of multi-GNSS brings a better and wider range of positioning, navigation, timing (PNT) and atmospheric retrieval applications [1-6]. As compared to GPS-only case, the multiple constellation increases the satellites in common view, thus enabling a higher accuracy and more reliability in precise-point positioning (PPP). The higher redundancy of the multi-GNSS model also shortens the initialization time of PPP. The combination of multi-GNSS opens up a new stage of its applications, whereas processing multi-GNSS data are more challenging [7,8]. 
The influence of intersystem bias (ISB) cannot be ignored in multi-GNSS PPP and unreasonable modeling of ISB will adversely affect the positioning accuracy and convergence speed [9]. In order to explore a reliable processing strategy of ISB, further investigation of its characteristic is necessary. After rigorous formula derivation, the ISB estimated by PPP contains the satellite clock datum and the receiver-code biases. Many agencies providing precise products have their own processing strategy in orbit determination and clock estimation, resulting in different satellite clock datums. Moreover, new efforts are made to rethink the assumption of constant receiver-code bias, which is closely related to temperature [10]. Therefore, to analyze the characterization of ISBs, a proper way is considering different satellite clock datums in precise products, the receiver (and antenna) type and other related factors such like the ambient environment (temperature) of the receiver.

Extensive studies have reported the influences of the abovementioned factors upon the ISB estimation. The receiver-code bias remarkably affects the ISB in the relative positioning [11,12]. The ISB between GPS and GLONASS is related to receiver type, antenna type and time system offset [13]. The code ISBs of BDS GEO, IGSO and MEO satellites to GPS estimated by single point positioning (SPP) are consistent [14]. The purpose of analyzing the characterization of ISBs is to model them more properly in PPP, many investigations provide their suggested strategies. A simple way is modeling the ISBs as constant process in one day [15-18], while some studies model the ISB as random walk process [19]. There also exist some investigations which model the ISB as white noise in the estimation [20]. In more detail, Zhou et al. believes that estimating ISBs as random walk or white noise process is much more reliable in multi-GNSS PPP processing [21]. Liu et al. find that the ISBs estimated with the center for orbit determination (CODE) and Wuhan University (WHU) final precise products are stable, which estimated with Deutsches GeoForschungsZentrum (GFZ) final precise products vary to a significant extent. Therefore, they recommends that, in GPS/BDS PPP, modeling the ISB as constant process when using precise products from the center for orbit determination (CODE) and Wuhan University (WHU) and modeling ISB as random walk when using precise products from Deutsches GeoForschungsZentrum (GFZ) [21]. In addition, some studies propose a short-term ISB model to predict the ISB in GPS/BDS-combined PPP [19].

To the best of our knowledge, there are few studies take the variation of the receiver-code bias into consideration. Whereas the receiver-code bias is affected by temperature and even exists a variation of ten meters. As we know, the ISB estimated by PPP contains the receiver-code bias. The question is how the variation of receiver-code bias influences the ISB. In this work, we further investigate the characterization of GPS/BDS ISBs in different scenarios. Except for estimating ISBs based on precise products from CODE, WHU and GFZ, we select the stations equipped with receivers of the same type in different areas to study whether or not the ambient environment (typically the temperature) of the receiver affects the ISB. Furthermore, the ultra-short baselines with the same ambient environment were applied to analyze the influence of receiver and antenna type in the ISB. After the analysis of ISB characterization, we implement combined GPS and BDS PPP with modeling the ISB as time constant, random walk process and white noise. The comparison of positioning performances will provide the guidance in proposing the optimal modeling strategy of ISB.

The remainder of this work is organized as follows: In the subsequent section, we review the undifferenced GPS/BDS PPP model and present the processing strategy. Following this, we designed four experiments to analyze, respectively, the influences of satellite clock datum, receiver type, antenna type and ambient environment upon ISB characterization. We also conducted a GPS/BDS PPP experiment with modeling ISB in different manners to find the optimal strategy. Finally, the last section presents summaries and conclusions.

\section{Methods}

This section reviews the full-rank undifferenced GPS/BDS model and gives insight into the estimable ISBs in the model. In addition, it also presents the processing strategy in detail. 
The Undifferenced GPS/BDS PPP

Let us start with the original undifferenced observation equations. For a receiver-satellite combination $r-s$ at frequency $j$ in epoch $i$, the undifferenced code $P_{r, f}^{T, s}(i)$ and phase $L_{r, f}^{T, s}(i)$ observations are defined as [22]:

$$
\begin{aligned}
& P_{r, f}^{T, s}(i)=\rho_{r}^{T, s}(i)+c\left(\Delta t_{r}^{T}(i)-\Delta t^{T, s}(i)\right)+\mu_{f}^{T} I_{r, 1}^{T, s}(i)+T_{r}^{s}+b_{r, f}^{T}+b_{f}^{T, s}+\varepsilon_{p}^{T}(i) \\
& L_{r, f}^{T, s}(i)=\rho_{r}^{T, s}(i)+c\left(\Delta t_{r}^{T}(i)-\Delta t^{T, s}(i)\right)-\mu_{f}^{T} I_{r, 1}^{T, s}(i)+T_{r}^{s}+\lambda_{f}^{T} N_{r, f}^{T, s}+B_{r, f}^{T}+B_{f}^{T, s}+\varepsilon_{L}^{T}(i)
\end{aligned}
$$

where superscript $T$ represents the system (G for GPS and C for BDS). $\rho_{r}^{T, s}(i)$ is the geometric distance; $c$ is the speed of light; $\Delta t_{r}^{T}(i)$ and $\Delta t^{T, s}(i)$ are the receiver and satellite clock offsets; $I_{r, 1}^{T, s}(i)$ the (first-order) slant-ionosphere delay on the first frequency with its coefficient $\left(\mu_{f}^{T}=\lambda_{f}^{2} / \lambda_{1}^{2}\right.$, in which $\lambda_{f}$ is the wavelength); $T_{r}^{s}$ is the tropospheric slant delay; $b_{r, f}^{T}$ and $b_{f}^{T, s}$ are the receiver and satellite code biases; $N_{r, f}^{T, s}$ is the integer ambiguity; $B_{r, f}^{T}$ and $B_{f}^{T, s}$ are receiver and satellite phase biases; $\varepsilon_{P}(i)$ and $\varepsilon_{L}(i)$ are noise in code and phase observation. Except $N_{r, f}^{T, s}$ (unit: cycle), $\lambda_{f}$ (unit: m/cycle) and $\mu_{f}^{T}$ (without unit), all quantities are expressed in units of range.

Note that, the effects of phase windup, solid tide, ocean loading, relativistic effects, earth rotation have been corrected by corresponding models [23].

Conventionally, the IGS precise clock products absorb the ionosphere-free (IF) combination of satellite code biases as following [24]:

$$
\hat{\Delta} t^{T, s}(i)=\Delta t^{T, s}(i)-\left(\frac{\mu_{2}^{T}}{\mu_{2}^{T}-1} b_{r, 1}^{T}-\frac{1}{\mu_{2}^{T}-1} b_{r, 2}^{T}\right)
$$

Equation (1) represents a rank-deficient system. In order to deal with the linear correlation between parameters (the receiver clock offsets with the receiver-code bias, the slant-ionosphere delay with the receiver-code bias, the ambiguities with the receiver and satellite phase biases, hardware biases between frequencies), the idea is to lump some of them together [25]. The reparameterization process is as below:

$$
\begin{aligned}
& P_{f}^{T, s}(i)=\rho^{T, s}(i)+c\left[\Delta t_{r}^{T}(i)-\Delta t^{T, s}(i)\right]+\mu_{f}^{T} I_{r, 1}^{T, s}(i)+T_{r}^{s}+b_{r, f}^{T}+b_{f}^{T, s}+\varepsilon_{P}
\end{aligned}
$$

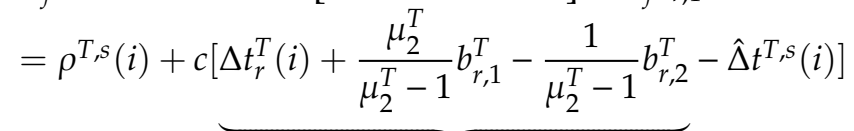

$$
\begin{aligned}
& \hat{\Delta} t_{r}^{T}(i) \\
& +\underbrace{\frac{c \mu_{f}^{T}}{\mu_{2}^{T}-1}\left(b_{r, 2}^{T}-b_{r, 1}^{T}+b_{2}^{T, s}-b_{1}^{T, s}\right)+\mu_{f}^{T} I_{r, 1}^{T, s}(i)}_{\mu_{f}^{T} \hat{I}_{r, 1}^{T,}(i)}+T_{r}^{s}+\varepsilon_{P}(i) \\
& L_{f}^{T, s}(i)=\rho^{T, s}(i)+c\left[\hat{\Delta} t_{r}^{T}(i)-\hat{\Delta} t^{T, s}(i)\right]+\mu_{f}^{T} \hat{I}_{r, 1}^{T, s}(i)+T_{r}^{s}+ \\
& \lambda_{f}^{T}\{\underbrace{N_{r, f}^{T, s}+B_{r, f}^{T}+B_{f}^{T, s}+\frac{c}{\lambda_{f}^{T}\left(\mu_{2}^{T}-1\right)}\left[\left(\mu_{f}^{T}+1\right)\left(b_{r, 2}^{T}+b_{2}^{T, s}\right)-\left(\mu_{f}^{T}+\mu_{2}^{T, s}\right)\left(b_{r, 1}^{T}+b_{1}^{T, s}\right)\right]}_{\hat{N}_{r, f}^{T, s}}\}+\varepsilon_{L}
\end{aligned}
$$


where ^ presents that the parameter after recombination. The full-rank GPS/BDS PPP observation equations can be rewritten as

$$
\begin{aligned}
& P_{f}^{T, s}(i)=\rho^{T, s}(i)+c\left[\hat{\Delta} t_{r}^{T}(i)-\hat{\Delta} t^{T, s}(i)\right]+\mu_{f}^{T} \hat{I}_{r, 1}^{T, s}(i)+T_{r}^{s}+\varepsilon_{P}(i) \\
& L_{f}^{T, s}(i)=\rho^{T, s}(i)+c\left[\hat{\Delta} t_{r}^{T}(i)-\hat{\Delta} t^{T, s}(i)\right]-\mu_{f}^{T} \hat{I}_{r, 1}^{T, s}(i)+T_{r}^{s}+\lambda_{f}^{T} \hat{N}_{f}^{T, s}+\varepsilon_{L}(i)
\end{aligned}
$$

We select the estimable GPS receiver clock $\hat{\Delta} t_{r}^{G}$ as reference, then the GPS/BDS ISB can be denote as

$$
\begin{aligned}
& I S B^{G, C}=\hat{\Delta} t_{r}^{C}-\hat{\Delta} t_{r}^{G} \\
& =\left(\bar{\Delta} t_{r}^{C}-\bar{\Delta} t_{r}^{G}\right)+\left(\frac{\mu_{2}^{C}}{\mu_{2}^{C}-1} b_{r, 1}^{C}-\frac{1}{\mu_{2}^{C}-1} b_{r, 2}^{C}\right)-\left(\frac{\mu_{2}^{G}}{\mu_{2}^{G}-1} b_{r, 1}^{G}-\frac{1}{\mu_{2}^{G}-1} b_{r, 2}^{G}\right) \\
& =\left(\Delta t_{r}^{C}-\Delta t_{r}^{G}\right)+\left(\Delta D^{G}-\Delta D^{C}\right)+\left(\frac{\mu_{2}^{C}}{\mu_{2}^{C}-1} b_{r, 1}^{C}-\frac{1}{\mu_{2}^{C}-1} b_{r, 2}^{C}\right)-\left(\frac{\mu_{2}^{G}}{\mu_{2}^{G}-1} b_{r, 1}^{G}-\frac{1}{\mu_{2}^{G}-1} b_{r, 2}^{G}\right)
\end{aligned}
$$

where $\bar{\Delta} t_{r}^{G}$ and $\bar{\Delta} t_{r}^{C}$ respectively represent the GPS and BDS receiver clock offset which absorb the satellite clock datum. $\Delta D^{G}$ and $\Delta D^{C}$ are GPS and BDS satellite clock datum, respectively. For the reason that the receiver and satellite clock parameters are linear dependent, a reference of clock offset must be set for each system [26]. In the meantime, the variation of the reference will be absorbed in the receiver clock offset. Therefore, the ISB obtained by PPP contains the offsets of inter-system satellite clock datums and the receiver-code biases.

The state vector $X$ of GPS/BDS undifferenced and uncombined PPP can be written as

$$
X=\left[\begin{array}{lllllll}
x & \hat{\Delta} t_{r}^{G}(i) & T_{r}^{s} & \hat{I}_{r, 1}^{G, S}(i) & \hat{I}_{r, 1}^{C, s}(i) & \hat{N}_{r, f}^{G, S} & \hat{N}_{r, f}^{C, s}
\end{array}\right]
$$

\section{Processing Strategy}

The final precise orbit ( 5 min interval for CODE and GFZ, 15 min interval for WHU) and clock products (30 s interval) from Wuhan University (WUM), center for orbit determination (CODE) and Deutsches GeoForschungsZentrum (GFZ) were employed. The absolute antenna phase-center correction models (igs14.atx) were applied to correct the phase-center offset and variation, which for BDS satellites obtained from European Space Agency (ESA). In order to analyze the characteristics of ISB, the ISB is modeled as white noise. The UNB3 model was used to correct the tropospheric dry delay and the tropospheric zenith wet delay is estimated as parameter, with Neil as the mapping function. The float phase ambiguities were estimated as constant for each continuous satellite arc. The traditional methods-turbo-edit detection-namely the geometry-free and MW observations were applied in the detection of cycle slip [27]. The elevation cutoff angle was set to $7^{\circ}$ and an elevation-dependent weighting scheme $\left(\sin ^{2}\right.$ (elevation)) for the observation was applied [28]. The weight ratio of GPS and BDS is set at 1:1.5 [29]. Due to the BDS GEO satellite orbit and clock accuracy, the weight of BDS GEO satellite observations is reduced by 10 times [30]. In order to strengthen the model, we estimated the ISBs with static PPP processing. The detail processing strategies are shown in Table 1. The distribution of the selected stations is shown in Figure 1.

Table 1. Adopted models and strategies.

\begin{tabular}{cc}
\hline Options & Processing Strategies \\
\hline System & GPS/BDS \\
Observation interval & $30 \mathrm{~s}$ \\
Estimation principal & Kalman filter \\
Frequency & L1,L2/B1,B2 \\
Elevation cutoff angle & $7^{\circ}$ \\
Receiver clock & White noise \\
Inter-system bias (ISB) & White noise \\
Ionospheric delay & White noise \\
Tropospheric delay & Random walk $\left(10^{-8} \mathrm{~m}^{2} / \mathrm{s}\right)$ \\
Receiver coordinates & Static \\
Ambiguities & Constant over time \\
\hline
\end{tabular}




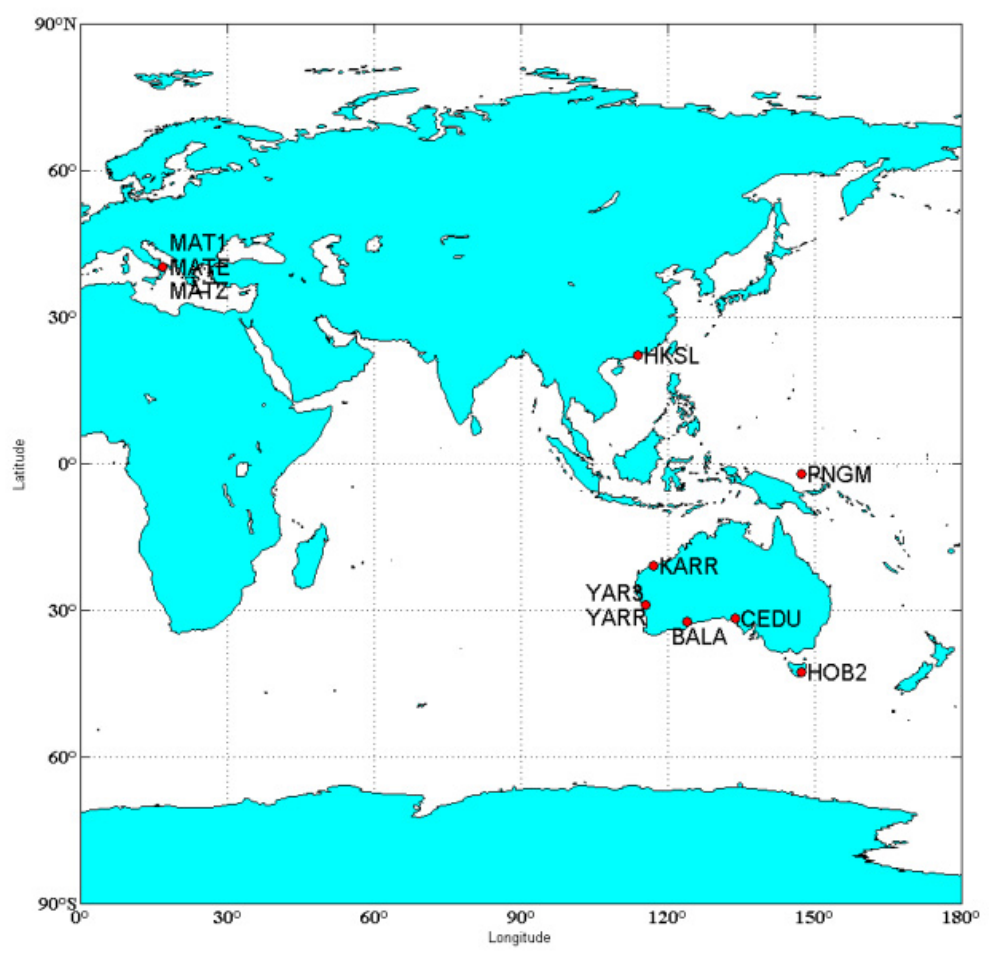

Figure 1. Geographic distribution of stations used in the global positioning system (GPS)/ BeiDou navigation satellite system (BDS) precise-point positioning (PPP) experiment to analyze the characteristic of inter-system bias (ISB).

\section{Characterization of ISB}

According to Equation (6), the ISB estimated by PPP contains the satellite clock datum and the receiver-code bias. In the following, undifferenced and uncombined PPP was adopted to analyze the influence factors of ISB. The technical features of the receiver and antenna types mentioned in the experiments are available in the official websites, TRIMBLE (https:/geospatial.trimble.com), LEICA (https://leica-geosystems.com), SETPENTRIO (https://www.septentrio.com).

\subsection{ISB Characterization Affected by the Satellite Clock Datum}

In this experiment, randomly, we collect data from three IGS stations including PNGM, HKSL and GAMG from day of year (DOY) 034-036, day of year (DOY) 128-130, day of year (DOY) 227-229, 2018, respectively. The observation data are available over FTP (ftp://cddis.gsfc.nasa.gov) for free.

The absolute ISBs estimated with different precise products differ a lot in magnitude. To show the results clearly, all estimates are subtracted by the ISB estimated in first epoch.

Figure 2 shows the ISB time series of three stations using WUH, CODE and GFZ precise products, respectively. The ISBs suddenly jump between two adjacent days, and the amplitude of the fluctuation is different-with-different precise products. This fluctuation is caused by the change of satellite clock datum [31]. Moreover, the daily ISBs based on CODE and WHU products are stable, while the variation of daily ISBs corresponding to GFZ products is remarkable. As we can see, the time series of ISBs from three stations using same products are consistent. It further proves that the change of satellite clock datum affects the ISBs. 

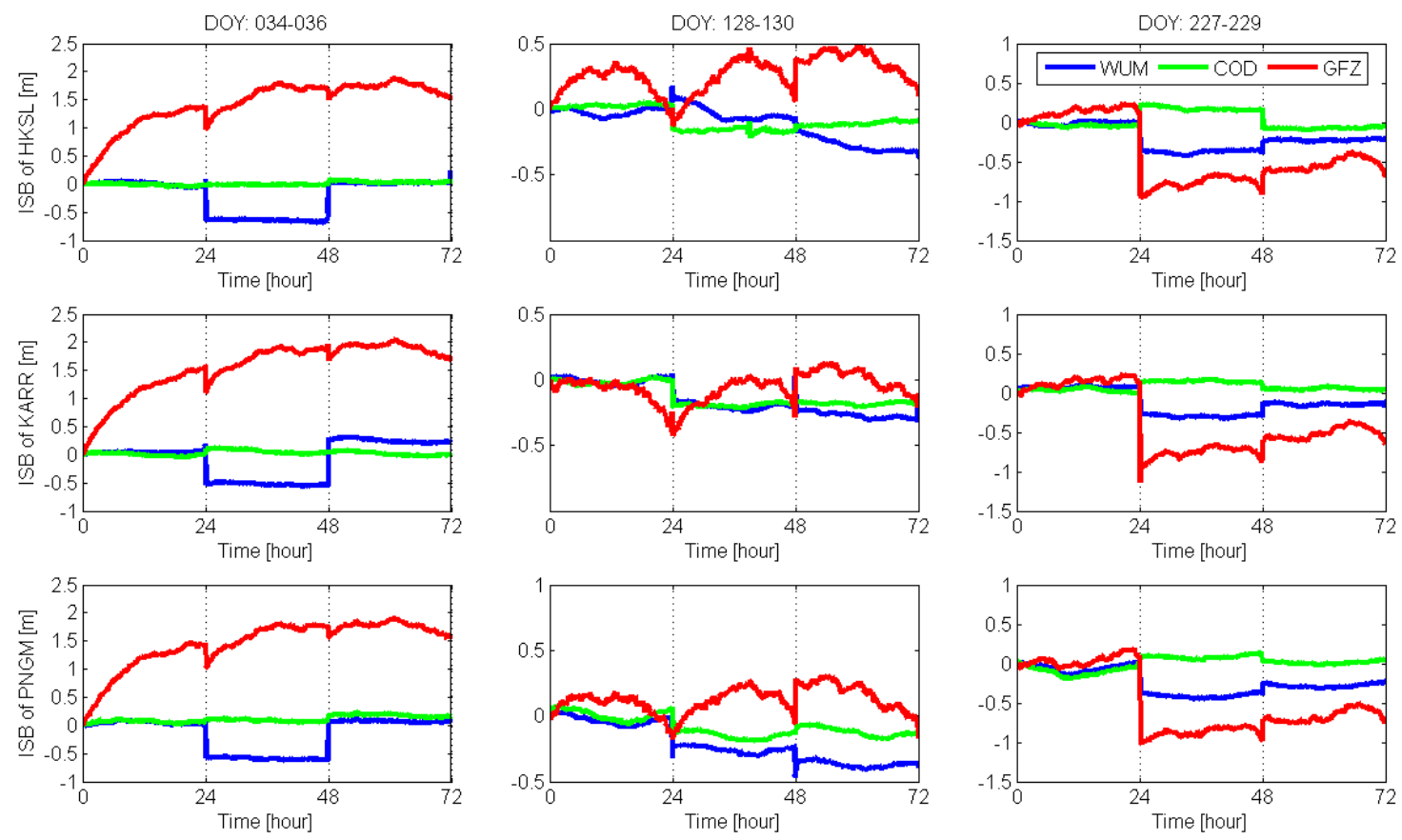

Figure 2. GPS/BDS ISB series from stations HKSL, KARR and PNGM stations estimated by using Wuhan University (WHU), Center for Orbit Determination (CODE) and Deutsches GeoForschungsZentrum (GFZ) precise products during DOY 043-036, 128-130 and 227-229, 2018.

\subsection{ISB Characterization Affected by the Ambient Environment}

Four IGS stations (CEDU HOB2 KARR and PNGM) are selected on DOY 002, 2018. Stations CEDU and HOB2 are equipped with SEPT POLARX5 receivers while stations KARR and PNGM are equipped with TRIMBLE NETR9 receivers. For more detailed information, see Table 2.

Table 2. Stations selected for the investigation of ISB characterization affected by the ambient environment.

\begin{tabular}{ccc}
\hline Station & Receiver type & Antenna type \\
\hline CEDU & SEPT POLARX5 & AOAD/M_T \\
HOB2 & SEPT POLARX5 & AOAD/M_T \\
KARR & TRIMBLE NETR9 & TRM59800.00 \\
PNGM & TRIMBLE NETR9 & TRM59800.00 \\
\hline
\end{tabular}

Figure 3 shows that the ISBs estimated with the WUM and CODE precise products showed little fluctuation. It is worth noting that even though stations KARR and PNGM were equipped with the same type of receivers and antennas, the ISB estimate were still different when using WUM and CODE precise products. We surmised that the ambient environment of the receiver, probably the temperature, may have affected the characterization of ISBs [10]. However, for the reason that the satellite clock datum of GFZ final products vary over time significantly, the difference between the different stations could not perform notably.

\subsection{Discussion}

Figure 3 shows that the ISBs obtained with even the same receiver and antenna type, they had little difference. Therefore, in order to investigate the receiver and antenna type affected the ISB characterization, we collected the data from ultra-short baseline (about several meters) stations to ensure the same ambient environments. We discuss the implication of receiver and antenna type in more detail below. 

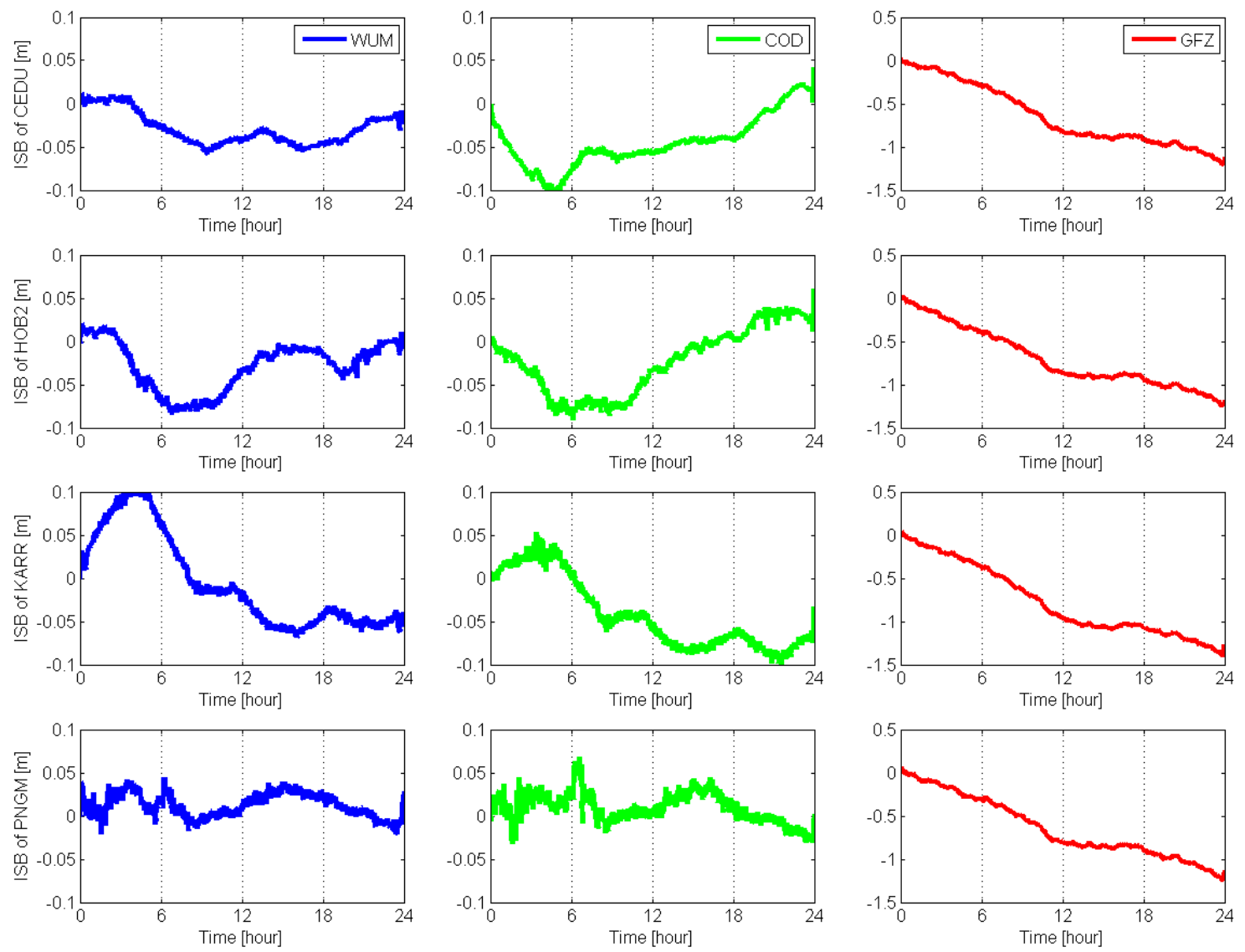

Figure 3. GPS/BDS ISB series of CEDU/HOB2/KARR and PNGM stations estimated using WHU, CODE and GFZ precise products on DOY 002, 2018.

\subsection{ISB Characterization Affected by the Receiver Type}

As shown in Table 3, this experiment selects two stations (MAT1, MATE) equipped LEICA GR30 receivers and one station equipped SEPT POLARX5TR receiver. All of them were connected to LEIAR20 antennas. The distance between any two of them was less than $30 \mathrm{~m}$. Therefore, we assumed that the external temperature of three stations was identical. For the reason that the observed BDS satellites were not enough, we only estimated the ISBs using WUM and GFZ products in this experiment due to the CODE precise products exclude the BDS GEO satellites. For the same reason, we skipped the data on DOY 254 and 256, 2018 and displayed the results on DOY 253, 255 and 257, 2018.

Table 3. Stations selected for the investigation of ISB characterization affected by the receiver type.

\begin{tabular}{ccc}
\hline Station & Receiver Type & Antenna Type \\
\hline MAT1 & LEICA GR30 & LEIAR20 \\
MATE & LEICA GR30 & LEIAR20 \\
MATZ & SEPT POLARX5TR & LEIAR20 \\
\hline
\end{tabular}

Figure 4 shows the ISB estimated from station MAT1, MAE1 and MAZ1. We see that the ISB time series from stations MAT1 and MATE equipped receivers with same type were consistent. However, see the results from station MATZ, which was equipped with the other type of receiver, the ISB estimates differed from the results from stations MAT1 and MAE1 in some periods. Typically, in the period of hour after 8 , there was an offset about $0.1 \mathrm{~m}$ between ISBs from two types of receivers when using WUM products. As we can see, the gaps of ISB estimated by different receiver types were similar, it due to the variation of the receiver-code bias was closely related to temperature [10], while the 
temperatures were comparable in the adjacent days. In addition, the ISBs based on WUM products were more stable than those based on GFZ products, which was in accordance with what we find in Figure 2.
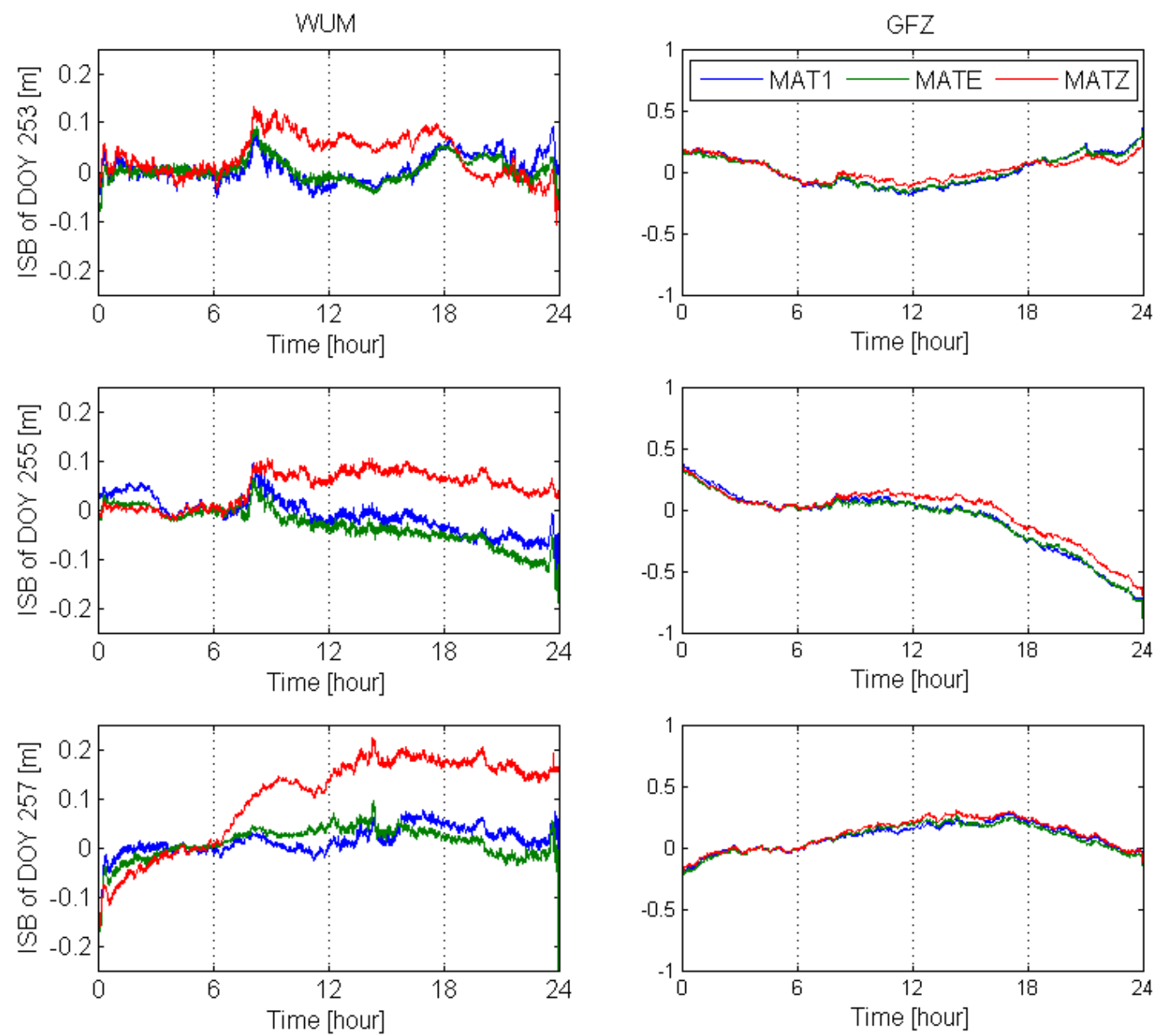

Figure 4. GPS/BDS ISB series of MAT1/MATE and MATZ estimated using WHU, CODE and GFZ precise products on DOY 253, 255, 257, 2018.

\subsection{ISB Characterization Affected by the Antenna Type}

This experiment aimed to find out whether the ISB characterization was related to antenna type or not. See Table 4, we select stations YARR and YAR3 equipped with the SEPT PLOARX5 receivers. Station YARR was connected to LEIAT504 antenna, while was YAR3 connected to LEIAR25 antenna. Similar as before, the distance between YARR and YAR3 was less than $30 \mathrm{~m}$, the external temperature of these two stations could be considered very similar.

Table 4. Stations selected for the investigation of ISB characterization affected by the antenna type.

\begin{tabular}{ccc}
\hline Station & Receiver Type & Antenna Type \\
\hline YARR & SEPT POLARX5 & LEIAT504 \\
YAR3 & SEPT POLARX5 & LEIAR25 \\
\hline
\end{tabular}

Figure 5 shows, the ISBs from different antennas were inconsistent when using WUM and CODE products, due to the smaller scales, the differences of ISB estimated with CODE precise products were more significant. This indicate that the ISB was related to antenna type and it may be caused by antenna and cable induced delay [32], thus making the ISB antenna-specific. However, the ISBs based 
on GFZ products were consistent, this was because the ISB variation caused by the change of satellite clock datum were much larger than the variation caused by the antenna code bias.
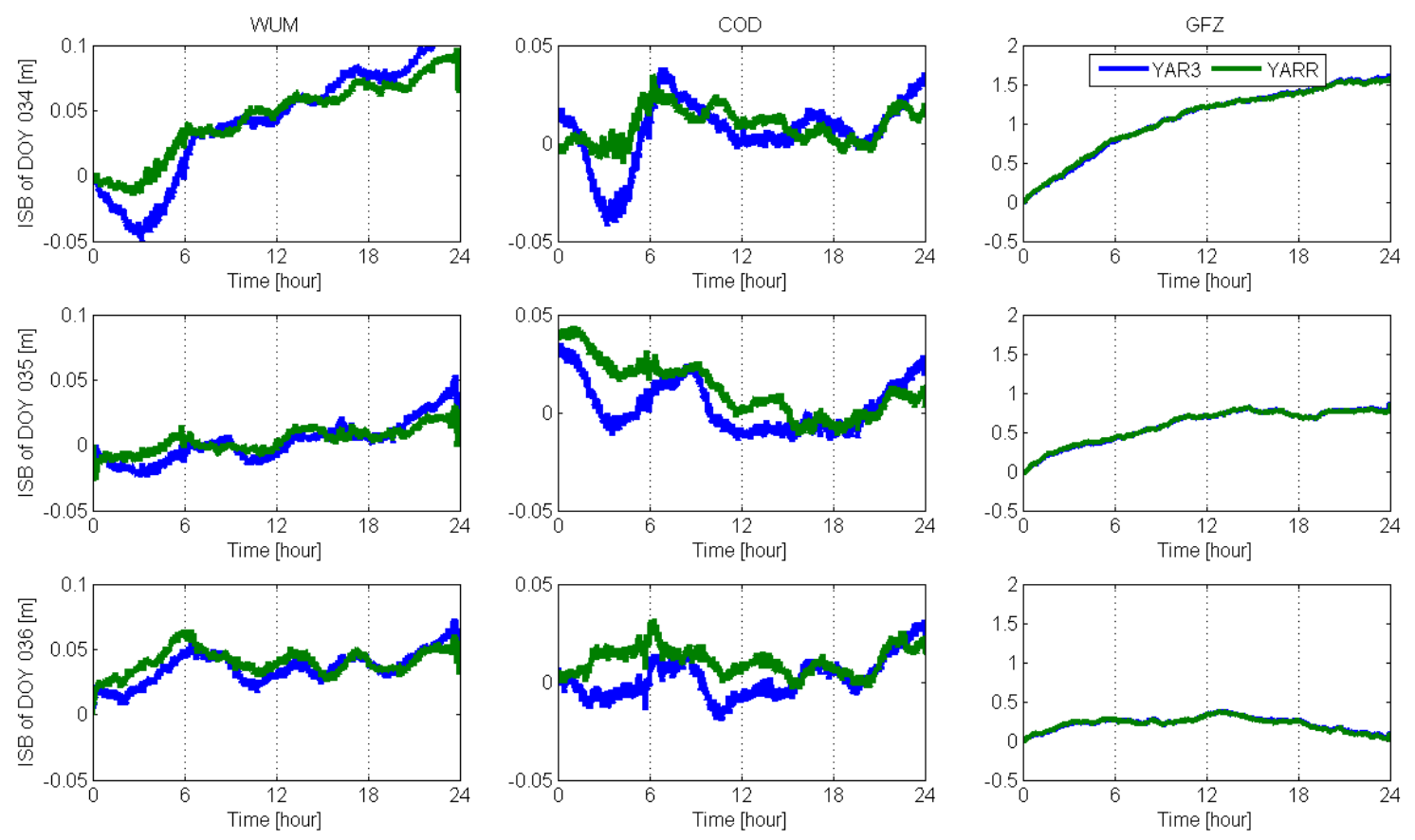

Figure 5. GPS/BDS ISB series of YARR and YAR3 stations estimated using WHU, CODE and GFZ precise products on DOY 034-036, 2018.

Based on the analysis of ISB characterizations, we carried out the GPS/BDS PPP with modeling the ISB as, constant (CT), random walk (RW) process and white noise (WN) [33], respectively. Data from twelve IGS stations on DOY 252-281, 2018 were used to analyze the performances of GPS/BDS float dynamic PPP using different ISB modeling strategies. Taking station PNGM as an example randomly, the GPS/BDS float dynamic PPP solutions were carried out with modeling ISB as constant, random walk and white noise process. As for the equipped receivers and antennas, refer to Table 2.

Figure 6 shows that, for the PNGM station, the positioning errors in east, north and up were almost the same with different modeling strategies of ISB using WUM and CODE precise products, while the solution using GFZ precise products, the performance with constant ISB modeling strategies were much worse than random walk and white noise ISB modeling strategies. Taken altogether, as Tables 5 and 6 , similar to the positioning performance, the convergence performances were almost uniform with different modeling strategies of ISB, the performances of GPS/BDS PPP based on CODE and WUM products were comparable. In these three cases, the CT process performs best, the RW process follows, and the $\mathrm{WN}$ process presents the worst performance. This was confirmed with the stability of ISBs based on CODE and WUM precise products. As for the results based on GFZ precise products, estimate the ISB as constant is not reasonable because it always performs great variation. Therefore, the results using RW and WN processing strategies were comparable, which were better than the results using CT processing strategy.

Table 5. RMS (cm) of GPS/BDS PPP result among different ISB modeling with different precise products.

\begin{tabular}{lccccccccc}
\hline & \multicolumn{3}{c}{ Constant } & \multicolumn{3}{c}{ Random Walk } & \multicolumn{3}{c}{ White Noise } \\
\cline { 2 - 10 } & Horizontal & Vertical & 3D & Horizontal & Vertical & 3D & Horizontal & Vertical & 3D \\
\hline WUM & 2.25 & 3.90 & 4.50 & 2.52 & 4.06 & 4.48 & 2.70 & 4.24 & 5.03 \\
COD & 2.02 & 3.68 & 4.20 & 2.29 & 3.84 & 4.45 & 2.46 & 3.91 & 4.62 \\
GFZ & 8.66 & 9.71 & 13.2 & 2.34 & 3.82 & 4.48 & 2.36 & 3.87 & 4.53 \\
\hline
\end{tabular}


Table 6. Average times (minutes) of GPS/BDS PPP result convergence to $10 \mathrm{~cm}$ in horizontal and vertical directions and maintained for one hour among different ISB handling methods with different precise products.

\begin{tabular}{ccccccc}
\hline & \multicolumn{2}{c}{ Constant } & \multicolumn{2}{c}{ Random Walk } & \multicolumn{2}{c}{ White Noise } \\
\cline { 2 - 7 } & Horizontal & Vertical & Horizontal & Vertical & Horizontal & Vertical \\
\hline WUM & 39.4 & 26.5 & 42.1 & 27.7 & 45.2 & 30.0 \\
COD & 37.5 & 25.3 & 40.4 & 25.9 & 44.7 & 29.2 \\
GFZ & 157.3 & 31.1 & 47.7 & 26.6 & 46.9 & 29.8 \\
\hline
\end{tabular}
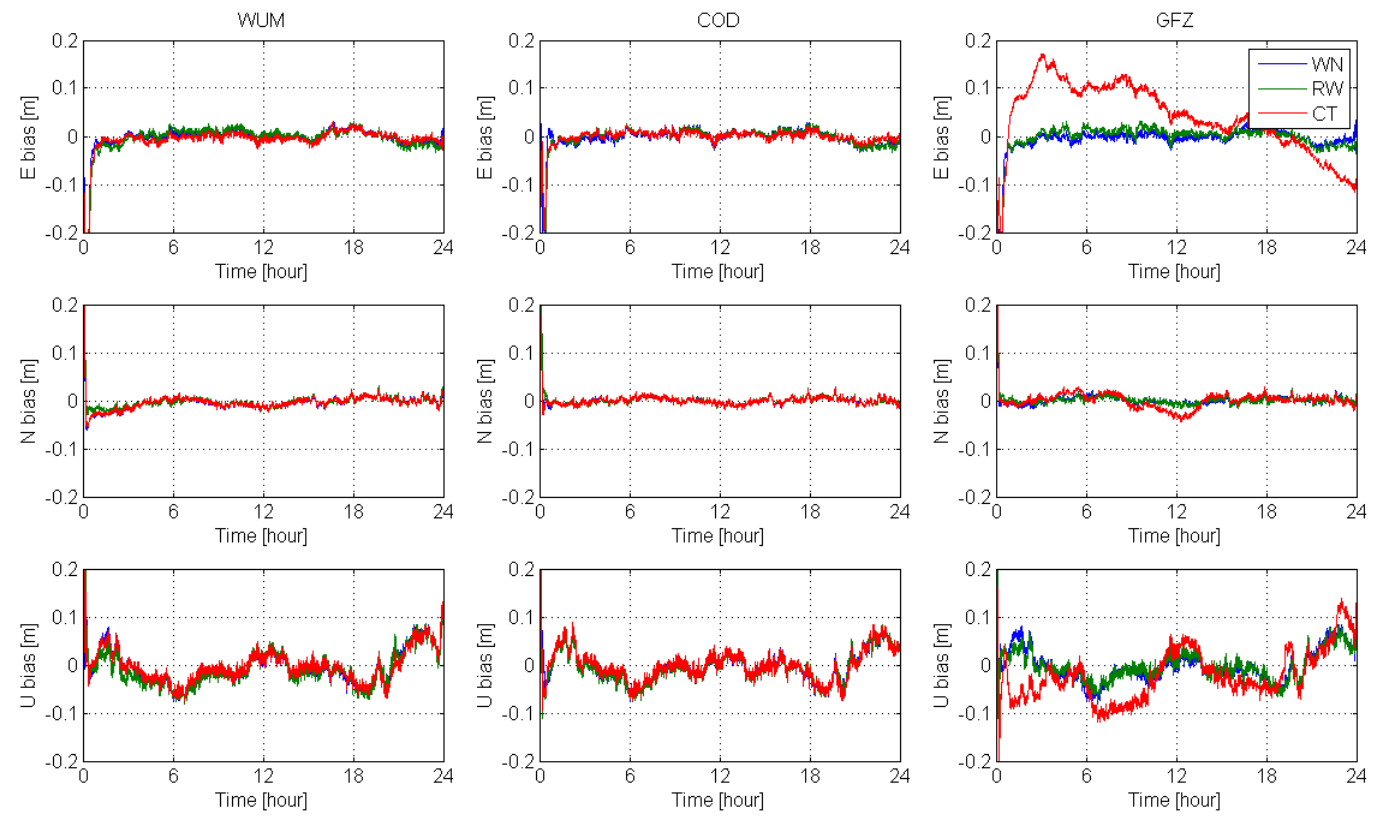

Figure 6. Positioning result of GPS/BDS PPP at station PNGM on DOY 252, 2018, using constant, random walk and white noise methods.

Consistently, the receiver-code biases from all the multi-GNSS experiment (MGEX) tracking stations demonstrate consistent stability as those from the stations we selected. Therefore, according to Table 5 and Figure 6, we came up with the results consistent with previous studies. However, the receiver-code bias was not always stable.

Peculiarly, we found that some stations varied significantly in receiver-code bias. Take the data from BALA on DAY 002, 2018 for example (besides GASC, JLCK, LAMB, MTDN, UCAL, etc. having the similar performance). This is freely available at Geoscience Australia FTP (ftp://ftp.ga.gov.au/). The station BALA is equipped with TRIMBLE NETR9 receiver and LEIAR25.R3 antenna.

As Figure 7 shown, the ISBs estimated by using CODE and WUM precise products were not always that stable due to the variation of receiver-code bias. Wrongly estimated the ISB as constant would carry out a terrible positioning performance as Figure 8 . Therefore, we suggest that estimating ISB as random walk or white noise was more reliable, instead of constant.
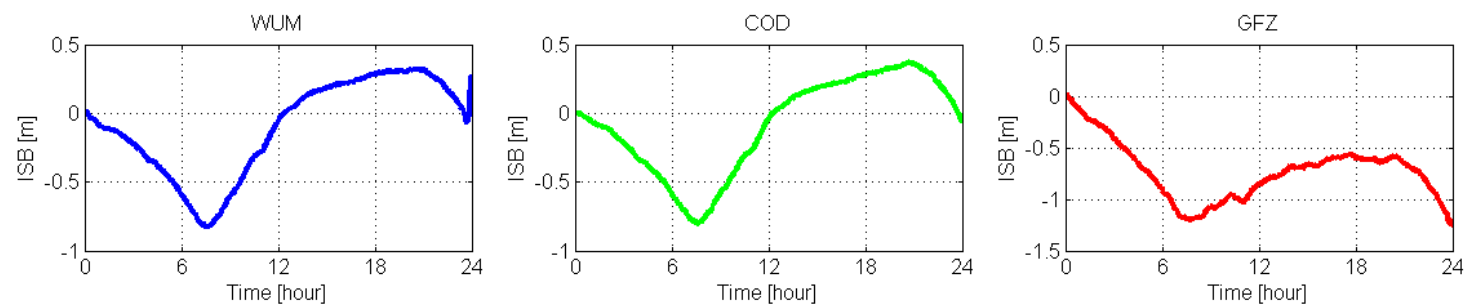

Figure 7. GPS/BDS ISB series of BALA WHU, CODE and GFZ precise products on DOY 002, 2018. 

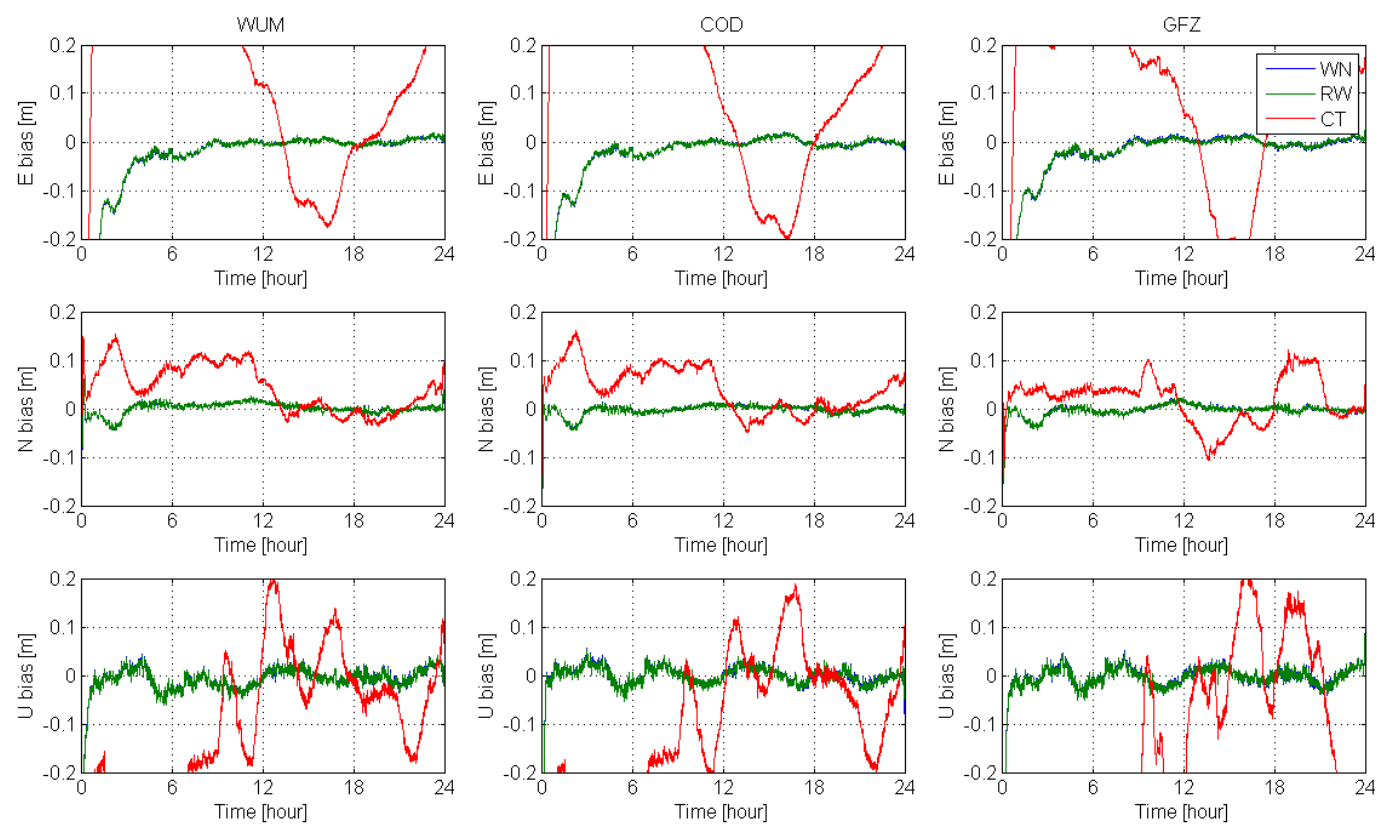

Figure 8. Positioning result of GPS/BDS PPP at station BALA on DOY 2, 2018, using constant, random walk and white noise methods.

\section{Summary and Conclusions}

In this contribution, we comprehensively analyzed the characterization of inter-system biases (ISBs) with different precise products, receiver types and antenna types. We also investigated whether or not the ambient environment of the receiver affects the ISB characterization. Based on the analysis of ISB characterization, we implemented the GPS/BDS PPP with modeling the ISB as time constant, random walk process and white noise.

A sudden jump exists in the ISB estimates between two adjacent days. It is caused by the change of satellite clock datum. The ISBs estimated with the precise products from different analysis centers have significant divergence. It is found that, in most cases, the estimated ISBs using WUM and CODE products are stable, while the variation of ISBs estimated by using GFZ products is remarkable. This is determined by the data processing strategies adopted in by different analysis centers. Moreover, even the stations equipped with the same type of receivers and antennas, the ISBs are inconsistent. This is because the stations are located in different places where the ambient environments (e.g., temperature) are different and the receiver-code biases are closely related to the temperature. The data from ultra-short baselines are used to confirm the same ambient environment, the result indicate that the receiver and antenna type both affects the characterization of ISBs. Therefore, besides the impact of different final precise products, the receiver type, antenna type and even the ambient environment affect the ISB characterizations.

For GPS/BDS PPP solutions with WUM and CODE precise products, the positioning performances agree well among the three ISB processing methods. However, when the receiver-code biases vary significantly and GFZ precise products are used, the results of GPS/BDS PPP obtained by random walk or white noise are more accurate than those using the constant method.

Author Contributions: Conceptualization, C.K.; methodology, C.K.; software, C.K.; validation, Y.Z.; formal analysis, Y.Z.; investigation, C.K.; resources, S.W.; data curation, S.W.; writing-original draft preparation, C.K.; writing-review and editing, Y.Z.; visualization, Y.Z.; supervision, S.W.; project administration, S.W.; funding acquisition, S.W. All authors have read and agreed to the published version of the manuscript.

Funding: This research was funded by National Key Research and Development Program of Shandong Province, Grant Number 2019JZZY010809. This work was supported by National Key Research and Development Program of Shandong Province, Grant Number No.2017GHY15116. 
Acknowledgments: We would like to thank the IGS multi-GNSS experiment (MGEX) and Geoscience Australia for providing Multi-GNSS data and precise products.

Conflicts of Interest: The authors declare no conflicts of interest.

\section{References}

1. Defraigne, P.; Baire, Q. Combining GPS and GLONASS for time and frequency transfer. Adv. Space Res. 2011, 47, 265-275. [CrossRef]

2. Gao, Z.; Zhang, H.; Ge, M.; Niu, X.; Shen, W.; Wickert, J.; Schuh, H. Tightly coupled integration of multi-GNSS PPP and MEMS inertial measurement unit data. GPS Solut. 2017, 21, 377-391. [CrossRef]

3. Li, W.; Wang, G.; Mi, J.; Zhang, S. Calibration errors in determining slant Total Electron Content (TEC) from multi-GNSS data. Adv. Space Res. 2019, 63, 1670-1680. [CrossRef]

4. Yuan, Y.; Wang, N.; Li, Z.; Huo, X. The BeiDou global broadcast ionospheric delay correction model (BDGIM) and its preliminary performance evaluation results. Annu. Navig. 2019, 66, 55-69. [CrossRef]

5. Zhang, B.; Chen, Y.; Yuan, Y. PPP-RTK based on undifferenced and uncombined observations: Theoretical and practical aspects. J. Geod. 2019, 93, 1011-1024. [CrossRef]

6. Zhang, B.; Teunissen, P.J.G.; Odijk, D. A novel un-differenced PPP-RTK concept. J. Navig. 2011, 64, S180-S191. [CrossRef]

7. Cai, C.; Gao, Y.; Pan, L.; Zhu, J. Precise point positioning with quad-constellations: GPS, BeiDou, GLONASS and Galileo. Adv. Space Res. 2015, 56, 133-143. [CrossRef]

8. Li, X.; Zhang, X.; Ren, X.; Fritsche, M.; Wickert, J.; Schuh, H. Precise positioning with current multi-constellation Global Navigation Satellite Systems: GPS, GLONASS, Galileo and BeiDou. Sci. Rep. 2015, 5, 8328. [CrossRef] [PubMed]

9. Zhou, F.; Dong, D.; Li, P.; Li, X.; Schuh, H. Influence of stochastic modeling for inter-system biases on multi-GNSS undifferenced and uncombined precise point positioning. GPS Solut. 2019, 23, 59. [CrossRef]

10. Zha, J.; Zhang, B.; Yuan, Y.; Zhang, X.; Li, M. Use of modified carrier-to-code leveling to analyze temperature dependence of multi-GNSS receiver DCB and to retrieve ionospheric TEC. GPS Solut. 2019, 23, 103. [CrossRef]

11. Odijk, D.; Teunissen, P.J. Characterization of between-receiver GPS-Galileo inter-system biases and their effect on mixed ambiguity resolution. GPS Solut. 2013, 17, 521-533. [CrossRef]

12. Dalla Torre, A.; Caporali, A. An analysis of intersystem biases for multi-GNSS positioning. GPS Solut. 2015, 19, 297-307. [CrossRef]

13. Chen, J.; Xiao, P.; Zhang, Y.; Wu, B. GPS/GLONASS system bias estimation and application in GPS/GLONASS combined positioning. In Proceedings of the China satellite Navigation Conference (CSNC) 2013, Wuhan, China, 15-17 May 2013; pp. 323-333.

14. Zeng, A.; Yang, Y.; Ming, F.; Jing, Y. BDS-GPS inter-system bias of code observation and its preliminary analysis. GPS Solut. 2017, 21, 1573-1581. [CrossRef]

15. Guo, J.; Li, X.; Li, Z.; Hu, L.; Yang, G.; Zhao, C.; Fairbairn, D.; Watson, D.; Ge, M. Multi-GNSS precise point positioning for precision agriculture. Precis. Agric. 2018, 19, 895-911. [CrossRef]

16. Li, X.; Ge, M.; Dai, X.; Ren, X.; Fritsche, M.; Wickert, J.; Schuh, H. Accuracy and reliability of multi-GNSS real-time precise positioning: GPS, GLONASS, BeiDou, and Galileo. J. Geod. 2015, 89, 607-635. [CrossRef]

17. Liu, T.; Yuan, Y.; Zhang, B.; Wang, N.; Tan, B.; Chen, Y. Multi-GNSS precise point positioning (MGPPP) using raw observations. J. Geod. 2017, 91, 253-268. [CrossRef]

18. de Bakker, P.F.; Tiberius, C.C. Real-time multi-GNSS single-frequency precise point positioning. GPS Solut. 2017, 21, 1791-1803. [CrossRef]

19. Jiang, N.; Xu, Y.; Xu, T.; Xu, G.; Sun, Z.; Schuh, H. GPS/BDS short-term ISB modelling and prediction. GPS Solut. 2017, 21, 163-175. [CrossRef]

20. Hong, J.; Tu, R.; Gao, Y.; Zhang, R.; Fan, L.; Zhang, P.; Liu, J. Characteristics of inter-system biases in Multi-GNSS with precise point positioning. Adv. Space Res. 2019, 63, 3777-3794. [CrossRef]

21. Liu, X.; Jiang, W.; Chen, H.; Zhao, W.; Huo, L.; Huang, L.; Chen, Q. An analysis of inter-system biases in BDS/GPS precise point positioning. GPS Solut. 2019, 23, 116. [CrossRef]

22. Leick, A.; Rapoport, L.; Tatarnikov, D. GPS Satellite Surveying; John Wiley \& Sons: Hoboken, NJ, USA, 2015.

23. Kouba, J. A Guide to Using International GNSS Service (IGS) Products; Kouba, Jan: Pasadena, CA, USA, 2009. 
24. Kouba, J.; Héroux, P. Precise point positioning using IGS orbit and clock products. GPS Solut. 2001, 5, 12-28. [CrossRef]

25. Odijk, D.; Zhang, B.; Khodabandeh, A.; Odolinski, R.; Teunissen, P.J.G. On the estimability of parameters in undifferenced, uncombined GNSS network and PPP-RTK user models by means of $\backslash$ mathcal $\{$ S $\}$-system theory. J. Geod. 2016, 90, 15-44. [CrossRef]

26. Han, S.; Kwon, J.H.; Jekeli, C. Accurate absolute GPS positioning through satellite clock error estimation. J. Geod. 2001, 75, 33-43. [CrossRef]

27. Blewitt, G. An automatic editing algorithm for GPS data. Geophys. Res. Lett. 1990, 17, 199-202. [CrossRef]

28. Wang, J.; Stewart, M.; Tsakiri, M. Adaptive Kalman filtering for integration of GPS with GLONASS and INS. In Geodesy beyond 2000; Presentation at the XXIIth International Union for Geodesy and Geophysics (IUGG); Springer: Berlin/Heidelberg, Germany, 2000; pp. 325-330.

29. Hou, P.; Zhang, B.; Yuan, Y. Analysis of the stochastic characteristics of GPS/BDS/Galileo multi-frequency observables with different types of receivers. J. Spat. Sci. 2019, 1-25. [CrossRef]

30. Pan, L.; Xiaohong, Z.; Fei, G. Ambiguity resolved precise point positioning with GPS and BeiDou. J. Geod. 2017, 91, 25-40. [CrossRef]

31. Zhang, H.; Hao, J.; Liu, W.; Yu, H.; Tian, Y. A Kalman filter method for BDS/GPS short-term ISB modelling and prediction. Acta Geod. Cartogr. Sin 2016, 45, 31-38.

32. Tegedor, J.; Øvstedal, O.; Vigen, E. Precise orbit determination and point positioning using GPS, Glonass, Galileo and BeiDou. J. Geod. Sci. 2014, 4, 65-73. [CrossRef]

33. Grewal, M.S.; Andrews, A.P. Kalman Filtering: Theory and Practice with MATLAB; John Wiley \& Sons: New York, NY, USA, 2014.

(C) 2020 by the authors. Licensee MDPI, Basel, Switzerland. This article is an open access article distributed under the terms and conditions of the Creative Commons Attribution (CC BY) license (http://creativecommons.org/licenses/by/4.0/). 